\title{
Problem-oriented training promotes spontaneous analogical transfer: Memory-oriented training promotes memory for training
}

\author{
DOUGLAS R. NEEDHAM and IAN M. BEGG \\ McMaster University, Hamilton, Ontario, Canada
}

\begin{abstract}
Spontaneous analogical transfer is the use of information from one problem to solve another problem, without an explicit hint to use the previous information. The results of five experiments were that if subjects tried to solve a training problem before hearing its solution, or tried to explain a training story's solution before hearing the correct explanation, spontaneous transfer was more likely than it was if subjects had studied the same training passage for memory before hearing its solution or explanation. The advantage of problem-oriented processing over memory-oriented processing occurred even though solution attempts nearly always failed, and the advantage was not reduced if the target problem was tested 15 min later rather than immediately after training. We propose that problem-oriented processes performed at study are appropriate processes to use at test. Further support for the account comes from subjects' memory for the training passages; the advantage for problem-oriented processing on solution tasks was mirrored by an equally substantial advantage for the memory-oriented subjects on a recall task.
\end{abstract}

Every day we face problems that need solutions, but many of them are reminiscent of earlier ones we have already solved. A smart strategy is to adapt a solution from an old problem rather than to devise a new plan of attack for each new problem. Many experiments show that information is readily transferred to a problem if subjects are told of the connection between the earlier information and the current problem. Without an explicit hint, however, subjects rarely spontaneously transfer previous information to problems for which it would be useful. We propose that subjects will be more likely to show spontaneous transfer if initial training entails processes that are appropriate for the test. In our experiments, we examined spontaneous transfer to target problems after subjects used problem-oriented processes or memory-oriented processes with analogous training problems. We will show that transfer is the rule rather than the exception if the training problems are ones that subjects have tried to solve or explain.

\footnotetext{
Funding was provided by Grant OGP0008122 from the Natural Sciences and Engineering Research Council of Canada to Ian Begg; a certificate of ethical approval is on file. Some of the research was part of a doctoral disseration by Douglas Needham, who was advised by Ian Begg, with Lee Brooks and Marianne Kristofferson on the committee. We also thank Ann Anas and Larry Jacoby of McMaster University, Mike Halldorson of the University of Manitoba, Brian Ross of the University of Illinois, and Mary Lamon and Bob Lockhart of the University of Toronto for helpful discussions. Some of this research was presented at the meeting of the Psychonomic Society, November 1990 . in New Orleans; we thank Gilles Einstein, Paula Hertel, Reed Hunt, Colleen Kelley, Steve Lindsay, Mark McDaniel, Janet Metcalfe, and Jeff Toth for sage advice after the talk. Reprints can be obtained from Douglas Needham or Ian Begg, Department of Psychology, McMaster University, Hamilton, Ontario L8S 4K1, Canada.
}

\section{Failures of Spontaneous Analogical Transfer}

A common finding in many experiments is that subjects seldom transfer relevant information to new problems without an explicit hint. For example, Weisberg, DiCamillo, and Phillips (1978) used Duncker's (1945) candle problem; the problem, to attach a candle to a wall, is solved by using a box as a platform. Before trying to solve the problem, subjects memorized a list of paired associates, one of which was candle-box, presented as words or as objects. Subjects who were told that one pair was relevant to the solution solved more problems than subjects who received no prior paired associates, but uninformed subjects did not. Thus, prior study of candlebox increased the number of correct solutions only if subjects knew of the connection between the pair and the problem.

Gick and Holyoak (1980) used Duncker's (1945) radiation problem, whose solution is to destroy a malignant tumor by attacking it with many low-intensity $\mathrm{X}$ rays from different directions simultaneously. Earlier, in a story comprehension task, subjects read an analogous story in which a general captures a fortress by dispatching small platoons along many roads to attack simultaneously. Transfer was observed if subjects were told that the previous analogue might be helpful. However, subjects rarely transferred the principle from the analogue to the target spontaneously, even if the experimenter explicitly stated the principle of the training analogue or provided a diagram of the principle (Gick \& Holyoak, 1983). Gick and Holyoak (1983, Experiment 4) found reliable spontaneous transfer if subjects read two analogues before tackling the radiation problem. Spencer and Weisberg (1986), however, did not observe spontaneous transfer when a new experimenter administered the target problem and 
it was presented in a different ink and typeface than were the two analogues.

Catrambone and Holyoak (1989) found higher solution rates on targets after subjects read and summarized three analogues rather than one, but only if subjects made specific comparisons among the analogues. They concluded that "presentation of fairly extensive comparison questions along with three analogs seems sufficient to enable reliable transfer to a superficially dissimilar target analog in the absence of [a hint]" (p. 1154). In these experiments, subjects worked with the three analogues and the target for about an hour, raising the possibility that they may have caught on to the experiment and expected the fourth problem (the target) to be similar to the first three. Even so, the amount of transfer was surprisingly low. In Experiment 4, for example, only about half the subjects solved the target after making comparisons among three training analogues.

Thus problem-solving by analogy is not a strategy that is commonly adopted by university students (see also Simon \& Hayes, 1976); it is unusual for more than half the subjects to show evidence of spontaneous transfer. Why do subjects fail to use the solution from a training problem to solve an analogous problem presented shortly thereafter in a similar context? Theories of problemsolving usually include four requisites for success in using an analogy to solve a target problem (e.g., Gick \& Holyoak, 1980; Holyoak \& Koh, 1987; Novick, 1988). Our gloss of the theories is that the solver must (1) encode the target problem in a way that (2) retrieves the encoded analogue and (3) selects the analogue rather than other information brought to mind during retrieval, and then (4) adapt the solution procedure from the analogue to the needs of the target problem. Hence transfer can fail to occur for many reasons, including misinterpretation of the target, failure to retrieve an analogue, selection of a nonanalogue, selection of an analogue whose solution was not adequately encoded in the first place, misapplication of the solution procedure encoded with the analogue, and so on.

Although there are many reasons for transfer to fail, subjects who are given hints generally achieve good solution rates on targets, implying that the needed information is available in memory and is accessible when cued appropriately. Therefore, failures of spontaneous transfer occur either because the target problem fails to retrieve the relevant information from memory, or because the information is retrieved but its relevance for the task at hand is not appreciated (cf. Ross, 1987). One approach to overcoming such failures is to train people to analyze problems to identify their key features. For example, Catrambone and Holyoak (1989) stated that "a fruitful avenue of research may involve searching for ways of helping learners to focus on relevant features of training examples in a variety of domains and to learn to reliably identify these features in transfer problems"' (p. 1154). Our approach is to focus on how people process training problems, with an eye to tailoring that process to be like the process needed to succeed on a target problem.

\section{Transfer-Appropriate Processing}

In the studies we have reviewed, subjects were encouraged to pay attention to meaning and to process information intelligently. For example, they read analogues so that they could summarize them from memory or they made comparisons among analogues. Although these processes are intelligent, active, and meaningful, much of what they entail is incidental to the explicit needs of a solver. We will focus on processing that is explicitly problem oriented.

The importance of problem-oriented processing can be seen in research using insight problems (Gardner, 1978), which people usually fail to solve despite having had relevant training. For example, Perfetto, Bransford, and Franks (1983) had subjects try to solve insight problems after rating the truth of statements that blatantly specified solutions to the problems. Only subjects who were told that the statements were relevant to the insight problems solved more problems than control subjects did. Bowden (1985) added a condition in which subjects had $2 \mathrm{~min}$, rather than $40 \mathrm{sec}$, to work on each problem. With the extra time, uninformed subjects solved as many problems as did subjects given a hint to use the previous information. However, Ross, Ryan, and Tenpenny (1989) used a different order of presenting the problems than Bowden did, and their subjects did not transfer solutions from the statements to the problems without an explicit hint. Stein, Way, Benningfield, and Hedgecough (1986) found spontaneous transfer of information from clue statements to insight problems, but only if the clue statements specified the solving principle and shared surface features with the problems. For example, the problem "The home was small because the sun came out; can you explain?" was solved more often if subjects rated "An igloo is a home that can be damaged by the sun" rather than "An igloo can be damaged by the heat" or "Some Eskimos live in igloos." Only the first clue statement presents "ig100 "' as a home in conjunction with the principle that the sun can be destructive.

Does the key to transfer lie in how people process training information? Lockhart, Lamon, and Gick (1988) proposed that the previous experimental procedures promoted learning of the information but did not require reconceptualization of that information. Hence the subjects may have acquired knowledge, but without the sagacity (cf. James, 1890/1950) to apply the knowledge to a new problem. They found more evidence of spontaneous transfer after people had rated the comprehensibility of information that was in a puzzle-like form rather than in a declarative form. For example, the multiple-marriages problem (" $\mathrm{A}$ man who lived in a small town married twenty different women of the same town. All are still living and he never divorced a single one of them. Yet, he broke no law. Can you explain?') was solved more often if subjects rated 
"The man married several women each week because it made him happy" followed seconds later by "clergyman" than if they rated "It made the clergyman happy to marry several women each week." They concluded that "problemsolving is facilitated by previously presented information when this information is presented in a form that requires for its comprehension the same conceptual processing as that demanded by the subsequent problem" (p. 42).

Adams et al. (1988) compared solution rates on insight problems after people had rated the truth of statements that were expressed either as problems or as facts. For example, the multiple-marriages problem was solved more often if subjects first rated "You can marry several people each week, if you are a minister" than if they rated "A minister marries several people each week"; the former is problem oriented, whereas the latter is fact oriented. Adams et al. proposed that the way people process problem-oriented statements is more like the processing that is appropriate for solving problems than is the way they process fact-oriented statements.

Adams et al. (1988) and Lockhart et al. (1988) proposed that transfer-appropriate processing is important for spontaneous transfer, but they operationally defined processing by manipulating the form in which information was presented to subjects. In our experiments, subjects received information in the same form but processed it differently. As well, their experiments used insight problems, whereas ours addressed the transfer of information from training problems to analogous target problems. However, we expected to find the same advantage for problem-oriented processing over memory-oriented processing that they found for puzzle-like forms over declarative forms and for problem-oriented forms over factoriented forms.

Other research on analogical transfer has considered the importance of problem-oriented training, but the results are equivocal. Novick (1988) had subjects try to solve several problems, guided by written descriptions of the solution procedures, before being tested on a problem that was analogous to one of the earlier problems. Subjects who were preselected as good problem solvers showed positive transfer, as we would expect, but poorer solvers showed negative transfer by using inappropriate principles from nonanalogous training problems. In Catrambone and Holyoak's (1989) Experiment 5, 91\% of subjects who were given a hint to use the first two analogues solved the third training analogue; these subjects then solved more target problems than did subjects who had read the third analogue (.83 vs. .64), as we would expect, but the difference was not reliable. Bassok and Holyoak (1989) found spontaneous transfer to physics problems after subjects had experience solving analogous algebra problems, but they did not find transfer from physics problems to algebra problems.

Nor is there much evidence that people transfer solutions from earlier mathematical problems to later ones. Reed, Dempster, and Ettinger (1985), for example, showed people equations and procedures for deriving correct answers, and then tested them on equivalent and similar problems. Even if the procedure was elaborated and explained, transfer was restricted to equivalent problems (see also Ross, 1987). A difference between these experiments and ours is that our subjects were asked to engage in problem-oriented processing, but they were left to their own devices, without experimenter-provided guidance about how to proceed.

\section{THE PRESENT EXPERIMENTS}

\section{Overview}

Our procedure was to have people process training analogues in problem-oriented or memory-oriented ways before attempting to solve target problems; between these two events, the experimenter explained each solution principle. To anticipate, we found that solutions from training were more likely to be transferred spontaneously to target problems after problem-oriented training than after memory-oriented training. The advantage for problemoriented training was obtained if the training analogues were presented as stories or as unsolved problems, if the attempts to solve the targets followed training immediately or after a delay, and if the orders in which targets were tested were different from those in which training analogues were experienced. The advantage for problemoriented processing was greatly reduced if the experimenter merely repeated the story without explaining its solution. Furthermore, the advantage for problem-oriented processing was restricted to problem-oriented testing. With a memory-oriented test-namely, recall of the training passages-it was the memory-oriented training that yielded the better performance.

\section{Problem Selection}

Our first task was to select difficult target problems. Twenty subjects received a booklet of 15 problems (adapted from Fixx, 1978; Gick \& Holyoak, 1983; Maier, 1931; Ross, 1987; and Wallechinsky \& Wallace, 1978) and spent 3 min trying to solve each problem. We chose the five problems whose solution rates were $10 \%$ or less; the problems are in the Appendix. Duncker's (1945) radiation problem has been used as the target in many previous experiments (see also Holyoak \& Koh, 1987; Keane, 1985), but we were unable to use it because it is discussed extensively in Gleitman (1986), which was the text for the students in our subject pool. We wrote alternate forms for each problem and tested them in pilot experiments. The analogues we used had different scenarios from the targets' but, like the targets, their mean solution rates were $10 \%$ or less; the analogues are in the Appendix.

\section{EXPERIMENT 1}

In Experiment 1, the training materials were five stories, each analogous to one of the target problems. After the subjects had spent 3 min with each training story, the experimenter explained why the solution in the final few lines of the story was the correct solution for the dilemma 
posed earlier in the story. After all five analogues had been presented, the five target problems were presented, and the subjects were given $3 \mathrm{~min}$ to try to solve each one.

The major variable was memory-oriented processing versus problem-oriented processing. Memory-oriented processors were asked to study each story so that they could recall it later. We chose memory-oriented processing because intentional memory instructions promote meaningful processing of materials but do not require subjects to conceive the stories as problems. As well, memory-oriented processing has ecological validity; it is our subjects' preferred way of preparing for examinations.

Problem-oriented processors were asked to try to explain why each solution was correct. In previous research, Chi, Bassok, Lewis, Reimann, and Glaser (1989) found an association between the quality of subjects' explanations of training problems and their success with target problems. Brown and Kane (1988) found that children's explanations of analogues were more effective in promoting transfer to a target than were explanations supplied by the experimenter. However, because we chose very difficult problems, we expected that few subjects would explain them well. Hence our research asked if the process of trying unsuccessfully to explain a solution would prepare the subject to incorporate the experimenter-provided explanation in a way that would increase the odds that the solution would be used later for an analogous target.

Finally, because previous experimenters had found that the order of presenting problems could affect the results, we used 15 orders of events within each of the orientations. It would be ideal to have each problem appear in each presentation position and be preceded and followed equally often by each other problem. However, it requires 10 orders of presentation to meet this objective for the five target problems, as well as 10 to balance the training analogues. We did not have enough subjects to fill the 100 orders for each of the memory and problem orientations. Our compromise was to use five orders of presenting the target problems and three orders of presenting the training analogues, for a total of 15 orders within each of the orientations.

\section{Method}

\section{Subjects}

The subjects for all experiments reported in this paper were students of introductory psychology at McMaster University who participated for course credit. For Experiment 1, 60 subjects assigned themselves to groups when they signed up for the experiment; groups were assigned at random to conditions. The 30 subjects who received each orientation were divided up into three groups of 10 subjects who received each of three orders of presenting the training stories; 2 subjects in each group received target problems in each of five orders

\section{Materials}

Each subject received a 10-page booklet. The first 5 pages contained the training stories, and the last 5 pages contained the target problems. The training stories appeared in three orders. In each order, the Two-String analogue was the fifth training story, and the Probability analogue was the first one; the other three training analogues were in three orders so that each of them was the second, third, and fourth story once. The five targets were presented in five orders so that each problem appeared once as the first, second, third, fourth, and fifth problem tested.

\section{Procedure}

All subjects were told they would receive a series of passages. Each training story was presented for $3 \mathrm{~min}$, after which the experimenter solved the problem and explained the solution. The solution required from 60 to $75 \mathrm{sec}$. Each target problem was also presented for $3 \mathrm{~min}$, during which time all subjects tried to solve the problems, writing their answers; targets were not solved by the experimenter. The subjects were reminded of the task before each passage. They were not told of the relationship between the target problems and training stories, and training stories could not be reconsulted.

Problem-oriented condition. Problem-oriented subjects were instructed to try to figure out why the solution stated in each story was correct. They were asked to work at understanding the solution, which they were assured was correct, so they could explain it if necessary. They were told to write down their explanations. They were encouraged to do their best while working with these difficult problems. After each attempt, the experimenter read the correct solution and its explanation to the subjects, using a blackboard to facilitate understanding. The blackboard was erased before the presentation of the next passage.

Memory-oriented condition. Memory-oriented subjects were told that they would have to remember some stories and solve some problems. They were told that they would have to recall the stories, so that they should work hard at remembering them. The tobe-remembered passages were the five training analogues, and the ones to be solved were the five target problems. Each training story was explained as in the solution condition.

\section{Scoring}

Attempted solutions were scored as correct or incorrect, using a strict scoring system; the few answers that noted the resemblance between problems without using the information from the first to solve the second were scored as incorrect. Solutions were scored independently by two individuals, one of whom was uninformed about the condition to which each subject belonged. Of the 300 protocols in Experiment 1, there were 12 differences of opinion; with further discussion, 4 were resolved in favor of the uninformed scorer and 8 in favor of the informed scorer. The good agreement occurred because it was usually obvious whether people had the right solution.

\section{Results and Discussion}

Throughout the article, alpha was set at .05 , and means are proportions accompanied by $M S_{\mathrm{e}}$ values from analyses of variance. The written explanations by the problemoriented subjects nearly always failed to capture the solution principle. Nevertheless, as the top row of Table 1 shows, the target problems enjoyed higher solution rates after problem-oriented processing than after memoryoriented processing $\left[.900>.693, F(1,58)=12.7, M S_{c}\right.$ $=0.0503$.

Of the 30 memory-oriented subjects, solutions were achieved by $21,21,18,22$, and 22 on the first through the fifth targets, respectively; the comparable numbers for the 30 problem-oriented subjects were $26,27,27,28$, and 27.

In Experiment 1, subjects engaged in problem-oriented processes or memory-oriented processes with five training stories, each of which posed a dilemma and then de- 
Table 1

Proportions of Targets Solved in Experiments 1, 2, 3, and 4

\begin{tabular}{lcc} 
& \multicolumn{2}{c}{ Processing } \\
\cline { 2 - 3 } & Problem-Oriented & Memory-Oriented \\
\hline Experiment 1 & .900 & .693 \\
Experiment 2 & & \\
$\quad$ Story form & .847 & .632 \\
$\quad$ Problem form & .882 & .609 \\
Experiment 3 & & \\
$\quad$ Story form & .876 & .610 \\
$\quad$ Problem form & .868 & .624 \\
Experiment 4 & & \\
$\quad$ Repetition condition & .696 & .582 \\
Recall condition & .620 & .563 \\
Recall score & .300 & .563 \\
\hline
\end{tabular}

scribed the solution to that dilemma. After each story, the experimenter explained why its solution was correct. After all five stories had been processed, the subjects attempted to solve five targets, each of which could be solved with the solution principle from one of the training stories. The finding was that the problem-oriented subjects solved more of the target problems than the memoryoriented subjects did. It is worth noting that the memoryoriented subjects solved over $60 \%$ of the targets, which makes the advantage for problem-oriented processing more impressive. Spontaneous transfer after problemoriented processing rivals the level of transfer found in previous research in which subjects were given explicit hints, although there are too many procedural differences to draw any conclusions from the similarity in solution rates. The following experiments explored the boundaries that might limit the value of problem-oriented processing for spontaneous analogical transfer.

\section{EXPERIMENT 2}

The purpose of Experiment 2 was to contrast the processing of the analogue with the form of the analogue. Experiment 1 used a story form for presenting the analogues; memory-oriented subjects studied training stories for memory, and problem-oriented subjects tried to explain why the solutions in the training stories were correct. The same two conditions were included in Experiment 2, but two new ones were added, in which the stories were reformed as problems by replacing each solution with an unanswered question. Memory-oriented subjects studied these problems for memory, and problem-oriented subjects actually tried to solve them. As in Experiment 1, each training passage was followed by an experimenterprovided explanation of the solution procedure. From the transfer-appropriate processing account, problem-oriented processing versus memory-oriented processing should have a larger effect on solution rates than problem form versus story form.

Tests of transfer were given after all analogues had been presented, as in Experiment 1. We added a condition in which the five targets were tested in the same order as that in which the analogues had been studied, in case presenting the targets in a different order disguised the fact that each target was very similar to one of the training analogues. In neither case did subjects have any way of knowing in advance that Event 6 in the experiment would be related to any of the first five events. The procedure is like the one used by Novick (1988), except that Novick's subjects had written instructions to guide them when solving the training problems.

\section{Method $^{1}$}

\section{Subjects}

For Experiment 2, 79 subjects received passages in problem form; 57 were tested in the order in which they had been trained, with 33 memory-oriented subjects and 24 problem-oriented subjects; 22 were tested in a different order, with 12 memory-oriented and 10 problem-oriented subjects. Another 76 subjects received passages in story form; 53 were tested in the order in which they had been trained, with 25 memory-oriented subjects and 28 problem-oriented subjects; 23 were tested in a different order, with 13 memoryoriented subjects and 10 problem-oriented subjects.

\section{Materials}

Each subject received a 10-page booklet in which the last 5 pages were the target problems. The first 5 pages were training analogues, which were either in problem form or in story form. The difference between forms was that in the story form the solution to the dilemma was stated in the final lines of the passage (see Appendix). The order of training passages was the same for all subjects (Order 2). The five targets were either in the order of the training analogues or in a different order (Order 1; relative to training, the test order was $4,3,5,2$, and 1 ). The average delay between a training analogue and its target was $15.75 \mathrm{~min}$ in each condition.

\section{Procedure}

As in Experiment 1, subjects spent 3 min with each training passage, after which the experimenter solved the problem and explained the solution. Target problems were also presented for $3 \mathrm{~min}$, during which time all subjects wrote their solutions. The subjects were reminded of the task before each passage, and they were not told of the relationship between the targets and training passages, which could not be reconsulted.

Problem-oriented conditions. Subjects who received training stories were treated identically to those in Experiment 1. Subjects who received training problems tried to solve them, writing down whatever came to mind when solving. After each analogue, the experimenter solved the problem and explained its solution as in Experiment 1.

Memory-oriented conditions. Subjects in memory-oriented conditions were told they would have to remember some passages and solve some problems. They were told that they would have to recall the passages, so that they should work hard at remembering them (this test was not administered). The passages to be remembered were the training analogues, and the ones to be solved were the target problems. Each training analogue was explained as in the solution condition. Note that subjects who received passages in story form received the solution twice-once in the training story, and once in the experimenter-provided explanation.

\section{Results and Discussion}

Problem-oriented subjects rarely succeeded during training. As in Experiment 1, written explanations of the stories were of very poor quality. Subjects who tried to solve training problems had solution rates of less than $5 \%$. 
In pilot experiments, solution rates for the five training analogues averaged $3 \%$, and solution rates for the five targets averaged $6 \%$ without training. The point is that, without training, solutions are very rare for the analogues and for the targets.

Transfer was assessed by solution rates on the five targets, and analyzed by a $2 \times 2 \times 2$ analysis of variance, with form (problem vs. story), orientation (problem vs. memory), and order (same vs. different) as factors. The only reliable effect was that the solution rate for problemoriented subjects exceeded that for memory-oriented subjects $\left[.864>.619, F(1,147)=60.0, M S_{\mathrm{e}}=0.039\right]$. As Table 1 shows, the advantage for problem-oriented processing versus memory-oriented processing was .847 versus .632 with story form and .882 versus .609 with problem form. Solution rates were similar for problem form versus story form (.727 vs. $.739, F<1)$ and for same versus different test orders (.745 vs. $.702, F<1$ ).

Problem-oriented processing is more likely than memoryoriented processing to promote spontaneous analogical transfer. Presenting passages in problem form or in story form had no effect on solution rates for transfer problems, even if the targets and the analogous training passages were tested in the same order. The solution rates after problemoriented training were over $80 \%$, which is well beyond the $5 \%$ rate enjoyed before training. Memory-oriented processing was also a reasonable way to train, achieving success rates of over $60 \%$.

\section{EXPERIMENT 3}

We conducted Experiment 3 to give memory-oriented subjects more opportunities to make use of training information to solve targets. In Experiments 1 and 2, all five training passages were processed before any target was attempted. In Experiment 3, each target was tested on the trial immediately following its training passage, which effectively created five "mini"' experiments, each with a different problem. Interleaving training and testing gives memory-oriented subjects an opportunity to develop strategies for attacking later problems, in response to their history of success and failure with earlier problems. If they spontaneously notice that any target is related to the immediately preceding training passage, they can approach the next training passages in problem-oriented ways. Hence the interleaved procedure presents more of a challenge for problem-oriented processing to exceed memory-oriented processing. As well, we retained the comparison between problem form and story form.

\section{Method}

\section{Subjects}

For Experiment 3, 156 students were assigned at random to conditions. Of 71 subjects who received the problem form, 33 were memory oriented and 38 problem oriented. Of 85 subjects who received the story form, 40 were memory oriented and 45 were problem oriented. Within each condition, problems were presented in three orders; respective numbers of subjects receiving Orders 1,2 , and 3 were 17,11 , and $5 ; 20,11$, and $7 ; 12,20$, and $8 ; 14$, 21 , and 10 .

\section{Materials and Procedure}

Each subject received a 10 -page booklet in which the evennumbered pages contained the five target problems. The page immediately preceding each target presented its training analogue, which was either in problem form or in story form. All instructions and information were the same as in Experiment 2. The only difference was in the sequencing of events. Each target problem was tested immediately after the training analogue had been solved and explained by the experimenter. Problem-oriented subjects tried either to solve problems or to explain the solutions in stories, and memory-oriented subjects worked at remembering the passages.

\section{Results and Discussion}

The written explanations by the subjects who tried to explain stories were as poor as in Experiments 1 and 2, and subjects who tried to solve the training problems achieved solution rates of less than 5\% in each of the three orders.

Transfer, assessed from performance on the five target problems, was analyzed by a $2 \times 2 \times 3$ analysis of variance, with form (problem vs. story), orientation (problem vs. memory), and the three orders as between-subjects factors. The only reliable effect was that of orientation $\left[F(1,144)=43.5, M S_{\mathrm{e}}=0.048\right]$; all other $F$ s were less than 1 , with nearly identical means for problem form versus story form (.755 vs. .751). Table 1 shows the advantage for problem-oriented processing over memoryoriented processing for subjects whose training was in story form (.876 vs. .610) and for subjects whose training was in problem form (.868 vs. .624$){ }^{2}$

Did subjects catch on that each training problem would be followed immediately by an analogous target problem? If subjects caught on, they should have been successful from that point on. That is, there should have been a higher probability of success if the preceding target had been solved correctly than if it had not. For problemoriented subjects, 37 of the 43 failures (86\%) were followed by success with the next problem; 255 of the 289 successes $(88 \%)$ were followed by success on the next target. For memory-oriented subjects, 73 of 121 failures (60\%) were followed by success, compared with 117 of 171 successes $(68 \%)$. These results do not imply that subjects caught on.

The advantage for problem-oriented processing over memory-oriented processing is robust. It occurs even if subjects are given interleaved opportunities to adjust their strategic attack on later problems. Once again, there were no effects of form when processing was controlled. Solution rates after problem-oriented training remained over $80 \%$, and solution rates for memory-oriented processing remained over $60 \%$, which is well beyond the $5 \%$ rate without training. Perhaps the memory-oriented processors failed to avail themselves of the chance to adopt problem-oriented processes because their solution rates were high enough to satisfy them.

We stress again that subjects who tried to solve training problems usually succeeded on targets that were based on the same principle, even though the subjects' initial attempts failed $95 \%$ of the time. Whatever processing transpires during the attempt allows the subject to grasp 
the solution in a way that increases the odds that it will be applied later to the appropriate target. These results remind us of the generation effect in the memory literature (Slamecka \& Graf, 1978). Those experiments entail problem-solving (Begg \& Roe, 1988; Jacoby, 1978), in that they usually present an item in an incomplete form and have subjects generate the complete form as a solution (e.g., generate ANALOGY from ANAL_GY). The size of the generation effect is the same, whether subjects produce the solution themselves or have it given to them by the experimenter after they have failed to produce it (Kane \& Anderson, 1978; Slamecka \& Fevreiski, 1983). That the generation effect survives even if the attempt fails implies that the generation effect is a result of whatever processing occurs during the attempt (Begg \& Snider, 1987; Begg, Snider, Foley, \& Goddard, 1989).

Like the research on the generation effect, the present research shows an advantage of advance effort for later performance. The advance effort is insufficient for later success because subjects cannot transfer a solution to another problem if they do not know the solution. One way to cast our results is to do so in terms of the generation effect: the attempt to generate followed by feedback led to greater transfer than did reading for memory followed by feedback. Our results can also be cast in terms of transfer-appropriate processing: the attempt to solve or explain uses the same processes as those that are needed to solve the target, whereas studying with memory in mind uses different processes than are required for solving the target. Blending these two castings is a good idea, because a "garden-variety" transfer-appropriate processing account fails to note the necessity of feedback after the initial attempt. We will ask, in the next experiment, whether merely performing the appropriate process is enough to promote transfer when no feedback follows the problem-oriented attempt.

\section{EXPERIMENT 4}

Experiments 1-3 have shown that problem-oriented training is superior to memory-oriented training for solving new problems that are similar to the training problems. The results are consistent with a transfer-appropriate processing account, but the account needs to be elaborated to include feedback; the materials are so difficult that the appropriate problem-oriented process rarely leads to a correct explanation of the solution. The experimenterprovided explanation of the training passage provided the necessary feedback. Levine (1974) noted that the value of feedback about subjects' hypotheses does not depend on the correctness of those hypotheses. A metaphor that captures our thinking is tilling the soil before planting a seed. Tilling has potential value, but tilling will be in vain without the seed; the seed has potential for growth, but the potential will be unrealized without the tilling. The metaphor stresses the joint necessity of advance preparation (cf. Ausubel, 1960) and the subsequent arrival of the right answer. In Experiment 4, we further examined the value of experimenter-provided information.

In Experiment 4, problem-oriented processing and memory-oriented processing were contrasted, using the interleaved procedure from Experiment 3. The experiments differed in what happened between training and testing. One condition was a repetition condition; the experimenter merely repeated the story without explaining it. Another condition was a recall condition, in which the experimenter did not repeat the story; instead, subjects tried to recall the story immediately after it was presented. We expect that the advantage for problem-oriented processing over memory-oriented processing for solving the target problems will be reduced or eliminated if the experimenter-provided feedback is replaced either with an experimenter-provided repetition of the story or with a subject-generated attempt to recall the story.

\section{Method}

Subjects

Experiment 4 included 73 subjects. For the repetition condition, 22 subjects received memory-oriented instructions, with 11 receiving each of two orders of problems, and 25 received problem-oriented instructions, with 11 and 14 in each of the two orders (Orders 1 and 3 ). For the recall condition, Order 3 was used, with 16 subjects receiving memory-oriented instructions and 10 receiving problem-oriented instructions.

\section{Materials and Procedure}

Experiment 4 was identical to the story conditions of Experiment 3, except for the period between training and testing on each problem. For the repetition condition, the experimenter reread the story without explaining the solution, and in the recall condition, subjects tried to recall the training story. They were told to recall the story in as much detail as possible, but to give at least its gist. They were told that point form was acceptable, and they were advised that, because they had just a minute or so, they should write quickly. The reason for the short time was to keep all parameters the same as in all the other experiments.

\section{Results and Discussion}

The advantage for problem-oriented processing over memory-oriented processing observed in each previous experiment was greatly reduced in Experiment 4 . For the repetition condition, the solution rate on targets after problem-oriented processing was arithmetically higher than the rate after memory-oriented processing (.696 vs. .582 ), but the difference was not reliable $[F(1,44)=2.03$, $\left.p=.16, M S_{\mathrm{e}}=0.074\right]$. For the recall condition, the difference was even less [.620 vs. $.563, F<1, M S_{\mathrm{e}}=$ $0.096]$. Hence repetition and recall are not substitutes for experimenter-provided explanation. Neither experimenterprovided repetition nor subject-generated recall allows subjects to cash in the potential value of problem-oriented processing during training. Problem-oriented training by itself is, therefore, not sufficient to promote transfer beyond the level shown by memory-oriented subjects.

Although subjects had very little time to recall the training stories, there was enough success to allow analyses. 
We scored the recall attempts in the same way as we had scored the solution attempts, to get a measure of recall of the solutions from the training stories. The outcome was that memory-oriented subjects recalled more of the solutions than problem-oriented subjects did [.563 > $.300, F(1,24)=4.81, M S_{\mathrm{e}}=0.0882$ ]. Solution rates were higher if training solutions were recalled than if they were not (gamma coefficients between recall and solution were .72 and .61 for problem-oriented and memoryoriented subjects, respectively), but there were many cases in which unrecalled solutions were correctly applied to problems. Problem-oriented subjects solved $87 \%$ of the targets whose solutions they recalled, but they managed to solve $51 \%$ of the targets whose solutions they failed to recall. Memory-oriented subjects solved $71 \%$ of problems whose solutions they recalled and $37 \%$ of problems whose solutions they failed to recall. In summary, there was a small and unreliable advantage in solutions for the problem-oriented processors over the memory-oriented processors, but a large and reliable difference in memory favoring the memory-oriented processors.

Experiment 4 showed that the advantage of problemoriented processing over memory-oriented processing is reduced or eliminated if subjects do not receive explanatory feedback after their attempt to explain the solution to a problem. The reduction of the advantage occurs if the experimenter repeats the story or if the subjects try to recall the story immediately before trying to solve the target. If one looks across the means in Table 1, it appears that removing the experimenter-provided explanation was more disruptive to problem-oriented processors than to memory-oriented processors.

A new finding from Experiment 4 is that memoryoriented training is superior to problem-oriented training if there is a memory-oriented test of free recall. Each of our previous experiments resulted in an advantage for problem-oriented training over memory-oriented training for solving analogous target problems. The advantage in recall of training stories for memory-oriented processing over problem-oriented processing is precisely what the idea of transfer-appropriate processing implies. Studying stories as problems promotes transfer of their solutions to new problems, but studying them as to-be-remembered stories promotes memory for the stories, including their solutions. Therefore, the reduced solution rates for the memory-oriented groups do not occur because subjects cannot recall the analogous solutions. We will explore further the relationship between initial orientation and the type of test in Experiment 5.

\section{EXPERIMENT 5}

The purpose of Experiment 5 was to examine further the dissociation between the processing used during training and the processing required at test implied by comparing across our experiments. In Experiment 4, memoryoriented subjects recalled more solutions than problemoriented subjects did, but the problem-oriented subjects were not at an advantage on the solving test, because the recall test replaced the experimenter-provided explanation of the training story. In Experiment 5, subjects approached a training story either as a to-be-explained problem or as a to-be-remembered story. The experimenter explained the solution as in Experiments 1,2, and 3 . Then subjects were asked either to recall the training story, or to solve a target problem; subjects tested for recall were then tested for solution of the target, and subjects tested for solution of the target were then asked to recall the preceding training story. Each subject worked with only one problem. We included only three of the problems (Poisoned Cups, Apples and Oranges, and Liar/Truth-Teller).

\section{Method}

\section{Subjects}

In Experiment 5, 142 subjects were assigned at random to 12 conditions, with from 9 to 14 subjects in each combination of orientation (memory vs. problem), test order (solve target, recall analogue vs. recall analogue, solve target), and problem (Poisoned Cups vs. Liar/Truth-Teller vs. Apples and Oranges).

\section{Materials}

Subjects who tried to solve the target before recalling the training story received a three-page booklet; the first page was the training story, the second was the target problem, and the third page was blank for the recall test. Subjects who recalled the training story before solving the target received a four-page booklet; the first page was the training story, the second page was blank for the recall test, the third page was also blank (with only one page some of the words of the target problem could be discerned through the paper), and the fourth page was the target problem. Booklets were assembled for each of the three problems used in the experiment.

\section{Procedure}

All subjects were told that they would work on two passages. Problem-oriented subjects and memory-oriented subjects were instructed as in the earlier experiments. The training story was presented for $2 \mathrm{~min}$, after which the experimenter repeated the solution and explained it. Target problems were also presented for $2 \mathrm{~min}$, during which time the subjects tried to solve them. On recall trials, which were either before or after the target, subjects had $2 \mathrm{~min}$ to recall the training story in as much detail as possible.

\section{Results and Discussion}

As in Experiment 4, recall data were scored as if they were attempted solutions, to allow a fair comparison between orientations. Mean solution and recall rates, averaged over the three problems, are in Table 2. The first analysis compared solution rates on the target problems with recall of the solutions from the training stories. The analysis was 2 (orientation) $\times 2$ (test order) $\times 3$ (problem) between subjects, with measure (solve or recall) within subjects. The outcome of the analysis was an interaction between orientation and measure $\left[F(1,130)=39.6, M S_{e}\right.$ $=0.174]$. The interaction was followed up by analyzing each task separately. For the solving task, the only reliable factor was orientation $\left[F(1,130)=9.91, M S_{\mathrm{e}}=\right.$ 0.238]; problem-oriented subjects solved more problems than memory-oriented subjects did $(.704>.440$; solu- 
Table 2

Proportions of Problems Solved and Stories Remembered in Experiment 5

\begin{tabular}{lcc}
\hline & \multicolumn{2}{c}{ Processing } \\
\cline { 2 - 3 } & Problem-Oriented & Memory-Oriented \\
\hline Solution then Recall & & \\
$\quad$ Solution rate for target & .686 & .485 \\
Recall of training story & .200 & .636 \\
Recall then Solution & & \\
$\quad$ Solution rate for target & .722 & .395 \\
$\quad$ Recall of training story & .278 & .579 \\
Means & & \\
Solution rate for target & .704 & .440 \\
Recall of training story & .239 & .608 \\
\hline
\end{tabular}

tion rates were similar if solving preceded or followed recall, .588 vs. $.554, F<1$ ). For the recall task, the only reliable effect was also orientation $\left[F(1,130)=21.9, M S_{e}\right.$ $=0.216$ ]; memory-oriented subjects recalled more solutions than problem-oriented subjects did $(.608>.239$; recall was similar if it was attempted before or after the solving task, . 432 vs. $.412, F<1$ ).

The recall data were also scored in terms of idea units from the training stories. The three stories presented 12 , 13 , or 14 idea units, each of which was scored as present or absent in recall. Memory-oriented subjects recalled more idea units than problem-oriented subjects did [.627 vs. $.412, F(1,138)=73.1, M S_{\mathrm{e}}=0.022$ ]; they also recalled more of the nonsolution ideas than problemoriented subjects did [.630 vs. $.426, F(1,138)=60.6$, $\left.M S_{\mathrm{e}}=0.024\right]$. Thus the advantage for the memoryoriented subjects over problem-oriented subjects is for all the ideas, including the solution and other aspects of the story.

The final analyses asked about the relation between recall and solving for subjects under each orientation, using data totaled over the two orders of testing and the three problems. The data are in Table 3 . The two orientations differed $\left(\chi^{2}=33.0, d f=3, N=142\right)$. The difference was because of the off-diagonals, which contributed $96 \%$ of the value of chi squared. People rarely succeeded on the incidental task if they failed on the intentional task; only 1 problem-oriented subject succeeded in memory but failed to solve the problem, and only 9 memory-oriented subjects succeeded with the problem but failed in memory.

The association between the two tests was stronger for problem-oriented subjects $\left(\gamma=.808 ; \chi^{2}=6.03, d f=1\right.$, $N=71)$ than for memory-oriented subjects $(\gamma=.417$;

Table 3

The Relationship Between Two Successive Tests: Recall of Training Stories Versus Solution of Target Problems

\begin{tabular}{cccccc}
\hline & \multicolumn{3}{c}{ Solution Test } \\
\cline { 2 - 6 } & $\begin{array}{c}\text { Problem-Oriented } \\
\text { Processing }\end{array}$ & & \multicolumn{2}{c}{$\begin{array}{c}\text { Memory-Oriented } \\
\text { Processing }\end{array}$} \\
\cline { 2 - 6 } Recall Test & Pass & Fail & & Pass & Fail \\
\hline Pass & 16 & 1 & & 23 & 20 \\
Fail & 34 & 20 & & 9 & 19 \\
\hline
\end{tabular}

$\chi^{2}=3.12, d f=1, N=71, p<.10$ ). Solution rates for problem-oriented subjects were .941 when recall succeeded versus .630 when recall failed; solution rates for memory-oriented subjects were .535 when recall succeeded versus .321 when recall failed. Recall rates for memory-oriented subjects were 719 for solutions of successfully solved problems versus .513 for unsolved problems; recall rates for problem-oriented subjects were .320 for the solutions of solved problems versus .045 for unsolved problems.

Experiment 5 provides clear evidence for a double dissociation of the type predicted by the idea of transferappropriate processing. Memory-oriented processing was superior to problem-oriented processing when the test was free recall. When the task was solution of the target, problem-oriented processing was superior to memoryoriented processing. Detailed analyses of the relationship between the two tests indicated that subjects were rarely successful on the incidental task if they failed on the intentional task to which their study was dedicated. Accordingly, the two measures were associated, although more strongly for the problem-oriented processors than for the memory-oriented processors. To the extent that problem solving is a measure of learning, we have clear evidence of learning without remembering and remembering without learning. Much past work has asked why people so often fail to use remembered solutions when they are faced with new problems that can be solved with those solutions. Future research will ask why people so often fail to recall solutions that they use spontaneously when faced with new problems.

\section{GENERAL DISCUSSION}

\section{Spontaneous Analogical Transfer}

We began the research to find out whether problemoriented processing would promote spontaneous analogical transfer more than memory-oriented processing does. We found that subjects who approach training passages as problems are very likely to apply the solution principles from those problems to target problems that are analogous to them, with solution rates that rival those found in previous research when subjects have been explicitly told of the relevance of the training information for the task at hand. The value of problem-oriented processing was independent of whether the information was presented in story form or in problem form, whether each target was tested immediately after training or no targets were tested until all training was finished.

Subjects in memory-oriented conditions received all the same information and experience as problem-oriented subjects, differing only in how they approached the training passages. Although the memory-oriented subjects fell short of the problem-oriented subjects in their later solution rates, they were successful in over $60 \%$ of their attempts, which is as good as the rate achieved by subjects in previous experiments that demonstrated transfer. Memory-oriented processing is a reasonably good training procedure, because it is a meaningful and intelligent 
approach to information. Indeed, its value makes the advantage of problem orientation more dramatic. We were disappointed that our memory subjects did not spontaneously adopt problem-oriented strategies over the course of attempting five interleaved training-target pairings. Perhaps the level of success was high enough to satisfy the subjects and not call their strategies into account.

Our findings support the conclusions of Lockhart et al. (1988) and Adams et al. (1988) that transfer is most likely if the to-be-transferred information is processed in a problem-like manner. However, we can go beyond those conclusions. First, Lockhart et al. (1988) and Adams et al. (1988) varied processing by presenting information in different forms; we have shown that the form of information has no effect when processing is controlled. Second, we have also shown that problem-oriented processing is not sufficient to promote transfer. Because the processing often fails to come up with the principle needed to solve the target, it is necessary for the experimenter to provide it; the potential value of problem-oriented processing remains unrealized if the experimenter-provided explanation of the principle does not occur.

\section{Transfer-Appropriate Processing}

Transfer-appropriate processing is a useful way to frame the results from many experiments. The idea, as originally stated by Morris, Bransford, and Franks (1977), was that a memory test is tacitly a test of transfer of training; they did not, however, include explicit transfer conditions. Begg (1976), who specifically measured transfer of training, found that the ability of nonsense syllables to serve as cues or as responses on a transfer test was dependent on how the syllables were learned; syllables trained to evoke images were good cues but poor responses in transfer, whereas syllables trained as responses to images were good responses but poor cues. We see transfer-appropriate processing as a complement to older ideas. McGeoch's (1942) law of context, for example, was that the excellence of performance was maximal if conditions of performance resembled conditions of learning. McGeoch had environmental stimuli in mind, but the concept is similar. Likewise, Thomson and Tulving's (1970) encodingspecificity principle shifted the focus to internal encodings, but the concept remains similar. The advantage we see for transfer-appropriate processing over these related ideas is that the explicit stress is on processing rather than on nominal or functional stimuli.

However, even an appropriate process cannot promote transfer if the process fails to come up with the needed principle and the environment also fails to deliver it. We have tried to capture this mutual interdependence by the metaphor of tilling the soil. Tilling is labor in vain unless a seed arrives, just as the seed's potential for growth will not be fulfilled unless the soil has been prepared for its arrival. Problem-oriented processing is advance preparation that will be in vain unless the solution principle becomes available, just as the potential value of the solu- tion principle will not be completely realized unless the subject is prepared for its arrival. However, the metaphor does not indicate why memory-oriented processors derive less benefit from the experimenter's explanation than the problem-oriented processors do. What is it about memory-oriented processing that reduces the value subjects gain from hearing an explanation of a problem's solution?

It is possible that the explanations were so fluent and well rehearsed that memory-oriented subjects understood the experimenter's words easily and failed to appreciate how difficult the problems were. Because problemoriented subjects had already failed to come up with an explanation on their own, they would be less likely to misattribute their easy understanding of the explanation to the easiness of the problem. Although we have no direct evidence that these misattributions occurred, there are many cases of similar types of misattribution in the memory literature. For example, Jacoby and Kelley (1987) had people rate the difficulty of anagrams that were presented alone (fscar) or with their solutions (scarf, fscar); anagrams with solutions were rated to be easier than anagrams alone, and the ratings were less predictive of actual difficulty as well. Similarly, subjects commonly attribute the ease of processing repeated items to perceptual clarity (Whittlesea, Jacoby, \& Girard, 1990), exposure duration (Witherspoon \& Allan, 1985), and background noise (Jacoby, Allan, Collins, \& Larwill, 1988). Likewise, easily processed items give an illusion of being memorable (Begg, Duft, Lalonde, Melnick, \& Sanvito, 1989).

Our brief tour of the memory literature gives a possible explanation for why problem-oriented processing and memory-oriented processing are not equally good ways to train for a test of problem-solving. The value of problemoriented processing is that it prevents subjects from mistaking easy understanding for easy problems; the disadvantage of memory-oriented processing is that it does not give subjects an opportunity to use their own solving experience as a guide to the difficulty of a problem. Crossfertilization with memory research has another important advantage. It calls our attention to the other side of transfer-appropriate processing. Memory-oriented processing is much better than problem-oriented processing as a way to study for recall.

\section{Dissociation of Solving from Remembering}

In these experiments, we were originally interested in analogical transfer, but we suspect that the dissociation between solving and recall will turn out to be more important. Recall was much better if people tried to remember stories than if they tried to explain them, but transfer to new problems was much better if people tried to explain the solutions than if they tried to remember the stories. The most dramatic finding was the number of people who successfully applied training solutions to target problems but failed to recall the solutions; of the 71 problem-oriented processors in Experiment 5, 50 solved 
the target problem, but the majority of them $(34 ; 68 \%)$ failed to recall the solution from the training story.

There has been much recent interest in the ways in which different tests reflect different ways that memory can influence current performance. For example, Roediger (1990) proposed that "performance on memory tests benefits to the extent that the cognitive operations at test recapitulate those engaged during initial learning" (p. 1049). Explicit tests, such as recall, direct the subject to remember material studied earlier in an experiment; "most explicit tests draw on the encoded meaning of concepts, or on semantic processing, elaborative encoding, and the like" (p. 1049). Implicit tests, such as word-fragment completion and perceptual identification, are affected indirectly by studied material: "most implicit tests rely heavily on the match between perceptual operations between study and test' (p. 1049). Most interestingly for our purposes, Roediger noted that failures of spontaneous analogical transfer resemble research done with implicit tests of memory; that is, the amount of transfer is generally small in the absence of explicit remembrance. By this account, our memory-oriented processors encoded the stories more semantically or elaborately than did the problem-oriented processors, who retained the stories in terms of perceptual operations that allowed the solutions to be produced on the implicit memory test, the solution test. A problem for this account is that most of our problem-oriented subjects who solved the target did so without explicit remembrance of the solution on the recall test.

We think our results reflect more than whether processes were meaningful as opposed to perceptual. It seems more likely that the processes were meaningful in different ways, and that their meanings cannot be defined adequately without making mention of the context of use. Solving a problem tests memory for the solution from a prior story indirectly, but it tests the applicability of that solution to a problem directly; recall tests memory for prior solutions directly, but tests their applicability to new problems only indirectly. From this point of view, our subjects did better on whichever task directly required them to perform in the way their initial processing prepared them to perform, and worse on whichever test required processing that was incidental to what they did. Much of what one does to prepare effectively for a test of memory is incidental to the needs of a test of problemsolving, and much of what one does to prepare effectively for solving problems is incidental to the needs of a test of recall. It should not be surprising that subjects can successfully apply a solution to a problem but fail to produce that solution when recalling training stories. The recalled solution and the applied solution may be the same string of words, but they do not have the same meaning, and understanding them in one sense does not imply that they have been understood in the other.

However the results are ultimately explained, they indicate that different laws underlie memory for training and transfer of that training to a new task. It is important that future research establish some boundaries for this dramatic dissociation. It would be depressing to think that if students remembered our lectures, they would be unlikely to use the principles we explained to them to solve problems later on.

\section{REFERENCES}

adams, L. T., Kasserman, J. E., Yearwood, A. A., Perfetto, G. A., Bransford, J. D., Franks, J. J. (1988). Memory access: The effects of fact-oriented versus problem-oriented acquisition. Memory \& Cognition, 16, 167-175.

Ausumel, D. P. (1960). The use of advance organizers in the learning and retention of meaningful verbal learning. Journal of Educational Psychology, 51, 267-272.

BAssok, M., HolyonK, K. J. (1989). Interdomain transfer between isomorphic topics in algebra and physics. Journal of Experimental Psychology: Learning, Memory, \& Cognition, 15, 153-166.

BEGG, I. (1976). Acquisition and transfer of meaningful function by meaningless sounds. Canadian Journal of Psychology, 30, 178-186.

BegG, I., Duft, S., Lalonde, P., Melnick, R., SANVtTo, J. (1989). Memory predictions are based on ease of processing. Journal of Memory \& Language, 28, 610-632.

BEGG, I., ROE, H. (1988). On the inhibition of reading by generating. Canadian Joumal of Psychology, 42, 325-336.

BEGG, I., \& SNIDER, A. (1987). The generation effect: Evidence for generalized inhibition. Joumal of Experimental Psychology: Learning, Memory, \& Cognition, 13, 553-563.

BegG, I., Snider, A., Foley, F., Goddard, R. (1989). The generation effect is no artifact: Generating makes words distinctive. Journal of Experimental Psychology: Learning, Memory, \& Cognition, 15, 977-989.

BOWDEN, E. M. (1985). Accessing relevant information during problem solving: Time constraints on search in the problem space. Memory \& Cognition, 13, 280-286.

Brown, A. L., KAne, M. J. (1988). Preschool children can learn to transfer: Learning to learn and learning from example. Cognitive Psychology, 20, 493-523.

Catrambone, R., * Holyoak, K. J. (1989). Overcoming contextual limitations on problem-solving transfer. Journal of Experimental Psychology: Learning, Memory, \& Cognition, 15, 1147-1156.

Chi, M. T., Bassok, M., Lewis, M. W., Reimann, P., Glaser, R. (1989). Self-explanations: How students study and use examples in learning to solve problems. Cognitive Science, 13, 145-182.

DUNCKER, K. (1945). On problem-solving. Psychological Monographs, 58(Whole No. 270).

FIXX, J. (1978). Solve it. New York: Fawcett Popular Library.

GARDNER, M. (1978). Aha! Insight. New York: Freeman.

GiCK, M. L., HolyoAK, K. J. (1980), Analogical problem solving. Cognitive Psychology, 12, 306-355.

Gick, M. L., HolyoAK, K. J. (1983). Schema induction and analogical reasoning. Cognitive Psychology, 15, 1-38.

Gleitman, H. (1986). Psychology (2nd ed.). New York: Norton.

HolyoAK, K. J., \& KoH, K. (1987). Surface and structural similarity in analogical transfer. Memory \& Cognition, 15, 332-340.

JACOBY, L. L. (1978). On interpreting the effects of repetition: Solving a problem versus remembering a solution. Joumal of Verbal Learming \& Verbal Behavior, 17, 649-667.

Jacoby, L. L., Allan, L. G., Collins, J. C., Larwill, L. K. (1988). Memory influences subjective experience: Noise judgments Journal of Experimental Psychology: Learning, Memory, \& Cognition, 14, 240-247.

JACOBY, L. L., \&ELLEY, C. M. (1987). Unconscious influences of memory for a prior event. Personality \& Social Psychology Bulletin, $13,314-336$

JAMES, W. (1950). The principles of psychology (Vol. 2). New York Dover. (Original work published 1890 ) 
KANE, J. H., \& ANDERson, R. C. (1978). Depth of processing and interference effects in the leaming and remembering of sentences. Journal of Educational Psychology, 70, 626-635.

KEANE, M. (1985). On drawing analogies when solving problems: A theory and test of solution generation in an analogical problem-solving task. British Journal of Psychology, 76, 449-458.

LEvine, M. (1974). A transfer hypothesis, whereby learning-to-learn, Einstellung, the PREE, reversal-nonreversal shifts and other curiosities are elucidated. In R. L. Solso (Ed.), Theories in cognitive psychology (pp. 289-303). Potomac, MD: Erlbaum.

LOCKHART, R. S., LAMON, M., GiCK, M. L. (1988). Conceptual transfer in simple insight problems. Memory \& Cognition, 16, 36-44.

MaIER, N. (1931). Reasoning in humans: II. The solution of a problem and its appearance in consciousness. Joumal of Comparative Psychology, 12, 181-194.

MCGEOCH, J. A. (1942). The psychology of human learning. Longman's Green, NY: David McKay.

Morris, C. D., Bransford, J. D., \& Franks, J. J. (1977). Levels of processing versus transfer appropriate processing. Journal of Verbal Learning \& Verbal Behavior, 16, 519-533.

Novick, L. (1988). Analogical transfer, problem similarity, and expertise. Journal of Experimental Psychology: Leaming, Memory, \& Cognition, 14, 510-520.

Perfetto, G. A., Bransford, J. D., \& Franks, J. J. (1983). Constraints on access in a problem solving context. Memory \& Cognition, 11, 24-31.

RoEdiger, H. L., III. (1990). Implicit memory: Retention without remembering. American Psychologist, 45, 1043-1056.

ReEd, S. K., Dempster, A., Etringer, M. (1985). Usefulness of analogous solutions for solving algebra word problems. Journal of Experimental Psychology: Learning, Memory, \& Cognition, 11, 106-125.

Ross, B. H. (1987). This is like that: The use of earlier problems and the separation of similarity effects. Joumal of Experimental Psychology: Learning, Memory, \& Cognition, 13, 629-639.

Ross, B. H., Ryan, W. J., Tenpenny, P. L. (1989). The access of relevant information for solving problems. Memory \& Cognition, 17, 639-651.

Simon, H. A., Hayes, J. R. (1976). The understanding process: Problem isomorphs. Cognitive Psychology, 8, 165-190.

SlameckA, N. J., FeVReisk, J. (1983). The generation effect when generation fails. Journal of Verbal Leaming \& Verbal Behavior, 22, 153-163.

Slamecka, N. J., Graf, P. (1978). The generation effect: Delineation of a phenomenon. Joumal of Experimental Psychology: Human Learning \& Memory, 4, 592-604.

SPenCER, R. M., \& Weismerg, R. W. (1986). Context-dependent effects on analogical transfer. Memory \& Cognition, 14, 442-449.

Stein, B. S., Way, K. R., Benningfield, S. E., \& Hedgecough, C. A. (1986). Constraints on spontaneous transfer in problem-solving tasks. Memory \& Cognition, 14, 432-441.

Thomson, D. M., \& Tulving, E. (1970). Associative encoding and retrieval: Weak and strong cues. Journal of Experimental Psychology, 86, 255-262.

Wallechinsky, D., \& Wallace, I. (1978). The people's almanac 2. New York: Kingsport.

Weisberg, R., DiCamillo, M., \& Philups, D. (1978). Transferring old associations to new problems: A nonautomatic process. Journal of Verbal Learning \& Verbal Behavior, 17, 219-228.

Whittlesea, B. W. A., JACOBY, L. L., \& GiRARD, K. (1990). Ilusions of immediate memory: Evidence of an attributional basis for feelings of familiarity and perceptual quality. Journal of Memory \& Language, 29, 716-732.

WITHERSPOON, D., AlLAN, L. G. (1985). The effect of a prior presentation on temporal judgments in a perceptual identification task. Memory \& Cognition, 13, 101-111.

\section{NOTES}

1. Experiments 2, 3, and 4 were designed as a package and conducted over 2 academic years, but they have been organized into three experi- ments for ease of exposition. Three orders of presenting the analogues were used over the experiments. They were Order 1 (Apples and Oranges, Two-String, Liar/Truth-Teller, Probability, Poisoned Cups); Order 2 (Poisoned Cups, Probability, Two-String, Apples and Oranges, Liar/Truth-Teller); Order 3 (Liar/Truth-Teller, Poisoned Cups, Probability, Two-String, Apples and Oranges). In conducting the experiments, groups were assigned at random to experimental conditions, except that comparable memory-oriented and problem-oriented conditions were always in consecutive groups. One group of subjects was tested in each of the conditions over the three experiments before a second group was tested in any of them, but not all conditions included a second group. The decision to stop was made because the results were very stable, even though some of the presentation orders included few subjects.

2. The three orders were equivalent: mean solution rates for memoryoriented processors were $.614, .613$, and .631 , and means for problemoriented processors were $.894, .844$, and .882 . Because of concerns expressed by a reviewer, we assessed the generality of the results by examining each of the 15 problem $\times$ position cells. For story form, all 15 comparisons were higher for problem-oriented processors than for memory-oriented processors; only 1 value was under .80 for problemoriented processors, compared to 11 for memory-oriented processors. For problem form, 14 of the 15 comparisons favored problem orientation; the exception was when the Two-String problem was the fourth one tested, in which case it was solved by $5 / 5$ memory subjects but only $6 / 7$ problem subjects. Only 2 values were under .80 for problem-oriented subjects, compared to 11 for memory-oriented subjects.

\section{APPENDIX}

Each target problem is presented in the form in which it was presented to the subjects. Following each target is the training analogue, presented both in problem form and in story form, and the text of the experimenter-provided explanation.

\section{Apples and Oranges}

\section{Target Problem}

A grocer ordered a box of apples, a box of oranges, and a box of apples and oranges from his distributor. A week later, the grocer received three boxes of fruit from the distributor. The boxes were labeled "oranges," "apples and oranges," and "apples." The distributor's representative warned the grocer that although the order had been filled correctly, each label on the boxes was wrong. The grocer realized that he could label each box correctly by selecting one fruit from just one box without looking inside. From which mislabeled box should the grocer select a fruit? Explain.

\section{Training Analogue}

A certain casino has three boxes of poker chips. One box is labeled " $\$ 5$ " and contains $\$ 5$ poker chips. The second box is labeled " $\$ 10$ " and contains $\$ 10$ poker chips. The third box is labeled " $\$ 5$ and $\$ 10 "$ and contains both $\$ 5$ and $\$ 10$ poker chips. One evening a prankster switched all the labels. He told the casino operator that although each label was wrong, he did not alter the contents of any of the boxes. The casino operator realized that by choosing just one chip from one of the boxes without looking inside, he could correctly label all three boxes.

Problem form. How could this be done?

Story form. He reached into the box mislabeled " $\$ 5$ and $\$ 10$." If he pulled out a $\$ 5$ chip, this crate must contain $\$ 5$ chips because all crates are mislabeled. Then, by a process of elimination, the others can be labeled. If a $\$ 5$ chip is drawn from the box, the box mislabeled " $\$ 5$ " must contain $\$ 10$ chips, and the box mislabeled " $\$ 10$ " must contain both $\$ 5$ and $\$ 10$ chips. Once the prankster's identity was determined, the casino operator decided to close his line of credit. 


\section{Experimenter-Provided Explanation}

In this passage, you are told of a casino operator who has three boxes of poker chips. One box is labeled $\$ 5$ and contains $\$ 5$ poker chips, a second box is labeled $\$ 10$ and contains $\$ 10$ poker chips, and the third box is labeled $\$ 5$ and $\$ 10$ and contains a mixture of both $\$ 5$ and $\$ 10$ poker chips. However, in the passage you are told that a prankster comes in and switches the labels on all three boxes, but he does not alter the contents of any of the boxes. The casino operator realizes that by reaching in and pulling out a chip from one of the boxes without looking inside, he can correctly label each box. Here's what he does. He reaches into the box labeled $\$ 5$ and $\$ 10$ and pulls out a chip. Whatever chip he pulls out of that box is the sole contents of that box, because all boxes are mislabeled. If he pulls out a $\$ 5$ chip from the box mislabeled $\$ 5$ and $\$ 10$, then he knows the box contains only $\$ 5$ chips because they cannot contain a mixture or else the label would be correct, and you are told in the passage that the prankster switched all three labels. Then, through a process of elimination you can correctly label the other two boxes. The box mislabeled $\$ 10$ must contain the mixture, and the box mislabeled $\$ 5$ must contain the $\$ 10$ chips. It might not do the casino operator any good to reach into either the box mislabeled $\$ 5$ or the box mislabeled $\$ 10$ because he cannot be certain that the chip he pulls out will allow him to correctly label that box. For example, if he reaches into the box mislabeled $\$ 10$ and pulls out a $\$ 5$ chip, he doesn't know whether that box contains solely $\$ 5$ chips or a mixture of $\$ 5$ and $\$ 10$ chips. So, by reaching into the box mislabeled as having the mixture inside and pulling out a chip, the casino operator can correctly label all three boxes. Whatever he pulls out is representative of the sole contents of that box, and through a process of elimınation, he can label all three boxes correctly.

\section{Poisoned Cups}

\section{Target Problem}

The King of a distant land sentenced an embezzler to death. Being a gambler at heart, the King offered the prisoner a way out. The King's attendant brought the prisoner two identical boxes, 10 cups labeled "poison," which were filled with some poisonous concoction, and 10 cups labeled "water," which were filled with ice-water. The attendant instructed the prisoner to distribute the cups any way he wished between the two identical boxes, but that he may not put all 20 cups into one box. When the task is finished, the King will at random reach into one of the boxes, pull out a cup, and force the prisoner to drink the contents of that cup. How should the prisoner arrange the cups so as to maximize his chances of living (i.e., maximize his chances of drinking water)?

\section{Training Analogue}

A street vendor sells navy shirts and white shirts. The vendor has two identical boxes, one for the white shirts and one for the navy shirts, and every day he starts out with 15 of each color of shirt. His boss, wanting to play a practical joke on his employee, mixed up the shirts between the two boxes, making sure, though, that neither box was empty. His boss told the janitor about the trick and the janitor in turn told the street vendor. So, the vendor opened up his two boxes before leaving the depot. Upon looking in them both, he realized that his boss had arranged them such that the probability of randomly selecting a navy shirt over a white shirt was maximized.

Problem form. How were the shirts distributed between the two boxes?
Story form. He saw that in one box there was 1 navy shirt. In the other box were 14 navy shirts and all the white shirts. The vendor laughed for a few seconds and threatened revenge.

\section{Experimenter-Provided Explanation}

In this passage, you are told of a street vendor who has two boxes of shirts. Ordinarily, he has 15 white shirts in one box, and 15 navy shirts in the other box. However, on this particular day, his boss has mixed up the shirts between the two boxes. His boss mixed up the shirts between the two boxes, ensuring that neither box was empty. The vendor was alerted to the prank, and opened up the boxes. When he opened them up, he found that the shirts had been arranged such that the probability of reaching into one of the boxes at random and randomly pulling out a navy shirt had been maximized. One box contained 1 navy shirt, and the other box contained 14 navy shirts and 15 white shirts. The reason why this maximizes the probability of selecting a navy shirt is this: If the vendor would reach into the left box, and there is a $50 \%$ chance he would randomly do this, then there is a $100 \%$ chance that he would pick out a navy shirt. It's the only shirt in the box. Multiply .50 and 1 and you get .50. If he should go to the right box, and there is a $50 \%$ chance that he would do this, there is a 14/29 chance of picking out a navy shirt. Multiply .50 and 14/29 together and you get about .25. When you add it all up, you get about a $75 \%$ chance of randomly picking out a navy shirt. If you try any other possible combinations of shirts, keeping in mind that no box may be empty, you will never get a value as high as $75 \%$. So, by putting 1 navy shirt in one box and everything else in the second box, the probability of randomly picking a navy shirt is maximized.

\section{Liar/Truth-Teller}

\section{Target Problem}

A traveler comes to a fork in the road and has no idea as to which way to go to reach his destination. There are two soldiers standing at the fork, and they both know which way is the correct way to go. One soldier is from Bedelred and he always lies. The other soldier is from Narex and he always tells the truth. The traveler knows that one soldier always lies while the other always tells the truth. Unfortunately, however, he does not know which is which. He may ask one soldier only one question to find out which direction he should take. What question should the traveler ask, and to whom?

\section{Training Analogue}

On a television quiz program's Bonus Round, the lucky contestant is given the opportunity to select one of two envelopes (a yellow one and a red one). Inside one envelope is a cheque for $\$ 25,000$. In the other envelope is a slip of paper informing the contestant that he/she has lost everything that was accumulated during the regular game. There are two models, each holding an envelope. The models know the contents of each envelope. The contestant is told that one model always lies and the other model always tells the truth. Unfortunately, the contestant is not told which is which. The contestant can ask only one question to one of the models to decide which envelope to select and hopefully win the $\$ 25,000$.

Problem form. What question should the contestant ask, and to whom, to guarantee that he/she wins the $\$ 25,000$ ?

Story form. After thinking it over for the allotted time limit of $30 \mathrm{sec}$, the contestant realized that by asking either model "what would the other model say is the correct envelope" and then picking the opposite envelope, he/she would win the 
$\$ 25,000$. Sure enough, he/she asked the question, and is now enjoying a cruise around the Caribbean.

\section{Experimenter-Provided Explanation}

The game show contestant is given the choice between two envelopes, one containing big money, the other containing bad news. With the two envelopes are two models, one of whom always lies and the other always tells the truth-and the contestant does not know which is which. The contestant is given one question to ask either of the two models which envelope to pick to win the money. Now the question the contestant asks must be appropriate to either model; that is, the question must yield the same answer from a liar and truth-teller, because the contestant does not know which is which. The question the contestant should ask to either of the models is this: "What would the other model say is the correct envelope to choose?" and then given this answer, the contestant would take the opposite. Let's suppose the lucky envelope with the money inside it is the red one. Let's suppose that the model you happen to ask is the liar. But, remember, you don't know which is which. So, you say to her, "What would the other model say is the correct envelope to choose?" You are, in fact, to her, saying, "What would the truth-teller say is the correct envelope to choose?" Well, the truth-teller would say to pick red, but since the liar lies, she'll say, "Oh, the other model would say to pick yellow" and then given this answer, the contestant would pick the opposite-red. Now suppose the model you happen to ask is the truth-teller. So you say to her, "What would the other model say is the correct envelope to choose?" You are, in fact, to her, saying, "What would the liar say is the correct envelope to choose?" Well, the liar would say to pick yellow, and since the truth-teller tells the truth, she'll say, "Oh, the other model would say to pick yellow," and then given this answer the contestant would pick red. So, asking either model what the other model would say and then picking the opposite will get the contestant the money.

\section{Probability}

\section{Target Problem}

The local weatherman is forecasting sun for the next full week. Each day, there is a 5/9 chance that it will be sunny, and a 4/9 chance that it will not be sunny. What is the probability that the first sunny day of the week is the sixth day of the week?

\section{Training Analogue}

The Toronto Blue Jays and the Montreal Expos are playing seven games for charity next week. Experts have concluded that for each game, there is a 2/7 chance that the Expos will win, and a 5/7 chance that the Blue Jays will win.

Problem form. If so, what is the probability that the first game the Blue Jays win is the fifth game they play?

Story form. Joe is in a betting pool and he has bet his life's savings that the first game the Blue Jays win is the fifth game that they will play against the Expos. Joe's wife is furious. She calculated that given that the experts are correct, the likelihood of Joe winning is less than $1 \%$. She reasoned that if the Blue Jays are to win first in Game 5, the Expos must win the first four games. The chances of the Expos winning one game is $2 / 7$; thus, the chance of winning four games in a row is $2 / 7 \times 2 / 7$ $\times 2 / 7 \times 2 / 7$. She then multiplied this result by $5 / 7$, the likelihood of the Blue Jays' winning Game 5. Needless to say, she plans on divorcing Joe.

\section{Experimenter-Provided Explanation}

The Toronto Blue Jays and the Montreal Expos are playing seven games for charity next week. For each game, there is a 2/7 chance the Expos will win, and a 5/7 chance that the Blue Jays will win. We are interested in the probability of the Blue Jays' first victory coming in the fifth game that they play out of the seven. So, we are not interested in the results of Games 6 and 7 . According to the problem, the Blue Jays must win Game 5 and there is a $5 / 7$ chance of them winning any game regardless of which one it is in the series, so for Game 5 , there is a 5/7 chance of a Blue Jays victory. Now, according to the problem, if that is to be their first win, they must lose the first four games. The odds of the Expos winning any game regardless of which one it is in the series is $2 / 7$, so the odds of winning the first four games straight is $2 / 7$ to the power of four; that is, $2 / 7 \times 2 / 7 \times 2 / 7 \times 2 / 7$. You then multiply this result by $5 / 7$, the odds of the Blue Jays' winning Game 5 . When you work out this probability, you get a result of less than $1 \%$.

\section{Two-String}

\section{Target Problem}

Before the Inaugural Gala, organizers were hurriedly trying to decorate the hall. Everything was nearly ready, and it was about ten minutes before the President-Elect was scheduled to arrive. Mr. Smith was decorating the walls and ceiling with balloons and party streamers made out of ribbon. He had nearly completed a fancy decoration pattern when he noticed two final pieces of ribbon were left dangling from the tiled ceiling above. He had planned to knot these two final pieces of ribbon together in order to attach balloons to them. However, when he grabbed the end of the green ribbon, he was unable to grasp the end of the blue ribbon at the same time. The ribbons could simply not be knotted together in this way. Since everyone had momentarily left the room, Mr. Smith thought that he would have to abandon this bit of decoration altogether. Suddenly, an idea struck him, and he was able to knot together these two ribbons. How?

\section{Training Analogue}

An adventurous explorer traveling through the jungles of Africa decided to stop for the night. Since the jungle he was exploring was full of snakes, he decided to sleep in a hammocklike device suspended over a babbling brook. He began unfolding the blanket that would serve as the base for the hammock. When he finished this, the explorer grabbed two vines hanging down and tied them together. This served as support for one end of the blanket. However, the two vines that were to support the other end presented some difficulty. When the explorer grabbed the end of one vine, it was impossible for him to grasp the end of the other vine at the same time. The two vines simply could not be knotted together in this way. The explorer thought he would have to give up and move camp elsewhere because these two vines from above could not be knotted together. Suddenly, an idea struck the explorer and he was able to knot together the two vines.

Problem form. How?

Story form. He took a rock and attached it to the end of one vine. Next, he grabbed the rock and vigorously swung the vine to which it was attached in the direction of the other vine. He then ran quickly to this other vine, grabbed it, and walked as close as possible to the swinging vine, which was now swinging back and forth. He then waited until the swinging vine came 
his way and caught it on the upswing. Now, while holding both vines, he removed the rock and knotted the two vines together. He was then able to enjoy a safe night's sleep.

\section{Experimenter-Provided Explanation}

In this passage, you are told of a jungle explorer who must tie two vines together to make this sleeping apparatus. However, when he tries to grab the one vine to bring it over to the other one to tie them, he finds that he cannot do it. The two vines are too far apart for him to grab onto at the same time. So, he takes a rock and attaches it to the end of one of the vines. The rock cannot be so heavy that it pulls the vine down and it cannot be that light that it will not allow him to turn the one vine into a pendulum. So, he sets the vine to which he attaches the rock in swinging motion. Then, while it's swinging, he runs over to the stationary vine, grabs it, and walks with it towards the vine that is now swinging. When the swinging vine comes back to him on the upswing, he can grab it, while still holding the other vine, and attach the two of them together. Because of pendulum motion, this solution works. So, by turning one of the vines into a pendulum, the explorer is able to attach the two vines together.

(Manuscript received November 5, 1990; revision accepted for publication May 31, 1991.)

\section{FUNDING OPPORTUNITY Applications Urgently Sought for Research on Management of Breast Cancer in Older Women}

Funds have been set aside by the National Institute on Aging, together with the National Cancer Institute and the National Center for Nursing Research, for investigator-initiated research on breast cancer diagnosis, management, and sequelae in women aged 65 and older.

Proposed research should focus on diagnostic evaluation of suspected breast cancers in elderly women, or treatment and follow-up of older patients with newly diagnosed breast cancer. Applications should address barriers to care in these areas, and development and testing of interventions to overcome these barriers. Approaches can range from psychosocial aspects of medical care (including patient/physician attitudes and decision making), to medical aspects of diagnosis, treatment, and continuing care, to health services issues of access and utilization.

The application receipt date is November 27, 1991. Letters of intent are encouraged and should be sent to Susan Nayfield, M.D., Program Director, Community Oncology and Rehabilitation, National Cancer Institute, EPN 300-D, 6130 Executive Boulevard, Bethesda, MD 20892 (301-496-8541). These letters will be reviewed by staff from all programs involved.

For age-related concerns, contact Marcia G. Ory, PhD, Behavioral and Social Research, National Institute on Aging, Bldg. 31, Rm. 5C32, Bethesda, MD 20892. 